\title{
The Effects of Beverage Type on Hypertension Mortality Rate in Russia
}

\author{
Y. E. Razvodovsky \\ Grodno State Medical University, Belarus, Grodno, str. Gorky 80, 230008 \\ *Corresponding Author: razvodovsky@tut.by
}

Copyright (C) 2014 Horizon Research Publishing All rights reserved.

\begin{abstract}
Background: Hypertension (HTN) is reported to be the leading contributor to premature death globally. It was repeatedly emphasized that excessive alcohol intake (binge drinking) is an independent risk factor for HTN. Recent research evidence suggests that the consumption of different types of alcoholic beverage may have a differential effect on HTN disease rate. Objective: The aim of this study was to examine the relation between the consumption of different beverage types and HTN mortality rates in Russia. Method: Time-series analytical modeling techniques (ARIMA) were used to examine the relation between the sales of different beverages and age-standardized sex-specific male and female HTN mortality data for the period 1980-2005. Results: Vodka consumption as measured by sales was significantly associated with both male and female HTN mortality rates: a 1 litre increase in vodka sales would result in a $10.8 \%$ increase in the male HTN mortality rate and $9.1 \%$ increase in the female rate. The consumption of beer and wine were not associated with HTN mortality rates. Conclusions: The present study suggests that HTN mortality tends to be more responsive to changes in spirits consumption per capita than to the wine or beer consumption. The findings from this study also suggest that public health efforts should focus on both reducing overall consumption and changing beverage preference away from distilled spirits in order to reduce cardiovascular mortality rates in Russia.
\end{abstract}

Keywords Hypertension, Alcohol Consumption, ARIMA Time Series Analysis, Russia, 1980-2005

\section{Introduction}

Hypertension (HTN) is reported to be the leading causes of mortality to which $13 \%$ of global deaths are attributed $[11,12]$. Raised blood pressure (BP) has been identified as a major risk factor for coronary heart disease and stroke [12]. Therefore, prevention and controlling HTN is one of the most cost-effective strategies for reducing the global burden of cardiovascular disease morbidity and deaths [11].
Considerable research evidence strongly supports the concept that alcohol is a major risk factor for development of hypertension $[1,7,8,9,10,13,19]$. Many population studies found evidence for a positive and linear association between alcohol consumption and incidence of HTN [7,10,34,38]. The Kaiser-Permanente Health Screening Survey involved more than 80.000 persons aged 15 to 75 years showed an average rise of 1 millimeter mercury systolic pressure for each standard drink per day [14]. A meta-analysis of the prospective studies reported a $40 \%$ increase in the relative risk of developing HTN in those drinking more than $25 \mathrm{~g}$ /day and a greater than fourfold increase in risk in those drinking more than $100 \mathrm{~g} /$ day [8]. In subjects, drinking $30 \mathrm{~g} /$ day or more, $20 \%$ of the incident cases of HTN were attributed to alcohol consumption [8].

It has been suggested that drinking pattern may be an important determinant of HTN independent of average consumption [32,34]. In particularly, Abramson et al. found higher level of ambulatory BP in binge drinkers after controlling for weekly drinking volume [1]. A comparative study of BP variation by day of the week in France and Northern Ireland found raised blood pressure on Mondays and Tuesday in Northern Ireland reflecting weekend binge drinking pattern, while no such effect was observed in France [17]. It has been also reported that binge drinking increases both systolic and diastolic blood pressure during period of intoxication [33].

Several lines of evidence suggest that different alcoholic beverages have differential effect on blood pressure. In particular, cross-sectional studies from the USA [15], Norway [5], France and Northern Ireland [17] suggest that beer and spirits consumption may be associated with higher BP than wine consumption. Alternatively, the results of the randomized controlled intervention study suggest that in healthy normotensive men, daily consumption of 40 grams of alcohol as either red wine or beer for 4 weeks results in similar increases in systolic BP [38]. Overall, studies examining beverage-specific effect of alcohol on BP have yield inconsistent results. In might be the case that the influence of the type of beverage on BP is modified by the patterns of alcohol intake, dietary and other lifestyle correlates. 
Russia is a country with a high prevalence of HTN [21,23]. According to the results of blood pressure measurement, the prevalence of hypertension among Russian men and women was $57 \%$ and $55 \%$ respectively [16]. The high level of alcohol consumption in combination with detrimental drinking pattern of spirits has been suggested as a crucial factor in the cardiovascular mortality crisis in Russia $[21,23,29,30,31]$. In a recent study the odds rations of high blood pressure for Russian men consuming $>1.2$ litres of alcohol per year were 2.35 (95\% CI 1.51-3.67) compared to non-drinkers [22]. It appears that beverage preference is an important determinant of the alcohol-blood pressure relationship in Russia. In a recent study, Akhmedjonov and Suvanculow using data from Russian Longitudinal Monitoring Survey, highlighted that frequent vodka and beer consumption increases the likelihood of high BP [2].

In line with this evidence, we assume that occasional heavy drinking of vodka in Russia should result in a positive association between vodka sales and HTN mortality at the aggregate level. In this study we will test the hypothesis of beverage-specific effect on HTN mortality by analyzing Russian's time series data between 1980 and 2005.

\section{Methods}

\section{Data}

The data on age-adjusted sex-specific HTN mortality rates per 1000.000 of the population are taken from the Russian State Statistical Committee (Rosstat). The Rosstat's cause of death classification has undergone several changes in recent decades. Until 1988 the cause of death classification was based upon the Soviet nomenclature which had a limited number of causes of death in comparison with the International Classification of Diseases (ICD) system. From 1989-1998 Rosstat used a coding scheme that was based on ICD-9. From 1999 a new coding system based on ICD-10 was introduced. Rosstat issued a table of correspondence between its classification system and ICD-9 and ICD-10 and it has been claimed that the Russian system of coding was and is compatible with the ICD. For example Soviet classification 400.09-404.99 "Hypertensive disease" corresponds with ICD-9 code 401.0-405.11 and with ICD-10 code I10.9-I15.9. The data on per capita beverage-specific alcohol sales (vodka, wine, beer in liters of pure alcohol) were taken from Rosstat's annual reports.

\section{Statistical Analysis}

To examine the relation between changes in the alcohol consumption and HTN mortality across the study period a time-series analysis was performed using the statistical package "Statistica". The dependent variables were the annual HTN mortality and the independent variables were aggregate beverage-specific alcohol sales. Bivariate correlations between the raw data from two time-series can often be spurious due to common sources in the trends and due to autocorrelation [19]. One way to reduce the risk of obtaining a spurious relation between two variables that have common trends is to remove these trends by means of a 'differencing' procedure, as expressed in formula:

$$
\nabla \mathrm{x}_{\mathrm{t}}=\mathrm{x}_{\mathrm{t}}-\mathrm{x}_{\mathrm{t}-1}
$$

This means that the annual changes ' $\nabla$ ' in variable ' $\mathrm{X}$ ' are analyzed rather than raw data. The process whereby systematic variation within a time series is eliminated before the examination of potential causal relationships is referred to as 'prewhitening'. This is subsequently followed by an inspection of the cross-correlation function in order to estimate the association between the two prewhitened time series. It was Box and Jenkins [4] who first proposed this particular method for undertaking a time series analysis and it is commonly referred to as ARIMA (autoregressive integrated moving average) modeling. We used this model specification to estimate the relationship between the time series HTN mortality and beverage-specific alcohol sales rates in this paper. In line with previous aggregate studies $[19,27,29]$, we estimated semi-logarithmic models with logged output. The following model was estimated:

$$
\nabla \operatorname{Ln} M_{t}=a+\beta \nabla A_{t}+\nabla N_{t}
$$

where $\nabla$ means that the series is differenced, M is HTN mortality rates, $a$ indicates the possible trend in HTN mortality due to other factors than those included in the model, $A$ is the beverage-specific alcohol sales, $\beta$ is the estimated regression parameter, and $N$ is the noise term. The percentage increase in HTN mortality rate rates associated with a 1-litre increase in alcohol sales is given by the expression: $\left(\exp \left(\beta_{1}\right)-1\right) * 100$. The temporal structure of the error term was estimated by using autoregressive (AR) or moving average (MA) parameters in the model. A diagnostic test for residual correlation is given by the Box-Ljung Q-test, which indicates whether the model has been adequately fitted.

\section{Results}

Descriptive statistics are presented in Table 1. Across the whole period the male stroke mortality rate was 1.25 times higher than the female rate (140.17 vs. 112.06 per 1.000 .000 ). The average per capita alcohol sales figure was 7.66 liters with vodka being the drink overwhelmingly consumed. However, these mean figures mask differing trends among the beverages across the period. While there has been a substantial drop in vodka sales from 5.96 liters in 1980 to 3.88 liters in 2005 and wine sales have remained at roughly the same level there has been a sharp growth in beer sales especially in recent years. Between 1998 and 2005 the per capita sales figure for beer rose from 1.16 to 3.08 liters.

The specification of the bivariate ARIMA model and outcome of the analyses are presented in Table 2. The analysis suggests that of the three beverages vodka alone 
was associated with HTN mortality in Russia. The estimated effects of vodka sales on the HTN mortality rate are clearly statistically significant for both sexes: a 1 liter increase in vodka sales would result in a $10.8 \%$ increase in the male HTN mortality rate and in $9.1 \%$ increase in female HTN mortality rate.

The general form of non-seasonal ARIMA model is $(p, d, q)$, where $p$ - the order of the autoregressive parameter, $d$ - the order of differencing, and $q$ - the order of the moving average parameter. Q test for residuals are satisfactory in all models.

Table 1. Descriptive statistics, Russia 1980-2005

\begin{tabular}{|lcc|}
\hline & $\underline{\text { Mean }}$ & $\underline{\text { Std. Dev. }}$ \\
Total alcohol sales (liters) & 7.66 & 2.03 \\
Vodka sales (liters) & 4.06 & 1.15 \\
Wine sales (liters) & 2.20 & 0.99 \\
Beer sales (liters) & 1.41 & 0.58 \\
$\begin{array}{l}\text { Hypertension mortality rate males (per } \\
1,000,000)\end{array}$ & 140.17 & 57.63 \\
$\begin{array}{l}\text { Hypertension mortality rate females } \\
\text { (per 1,000,000) }\end{array}$ & 112.06 & 44.98 \\
\hline
\end{tabular}

\section{Discussion}

According to the results of time-series analysis there was a positive and statistically significant effect of per capita vodka sales on HTN mortality in Russia. These findings provide indirect support for the binge drinking hypothesis, suggested that episodic heavy drinking of spirits is an important determinant of HTN mortality crisis in Russia $[18,35]$. The effects of drinking spirits may also be exacerbated by the way they are drunk as a heavy episodic drinking pattern is widespread. Moreover, this pattern of consuming alcohol is much more frequent when drinking spirits than other types of beverage among both men and women in Russia [18]. According to a recent study $28 \%$ of men and $4 \%$ of women consumed at least $200 \mathrm{~g}(86+\mathrm{g}$ of pure alcohol) on one occasion at least once every 2-3 weeks [24].

It is important to point out, that the size of the bivariate association between vodka sale and HTN mortality rates for men is only slightly higher than for women. It seems plausible that women are more sensitive to an increased risk of HTN, even at the relatively low levels of alcohol consumption. Indeed, in a systematic review of studies of moderate alcohol consumption in relation to blood pressure Burger et al. concluded that there were linear BP elevations at drinking levels of $>20 \mathrm{~g} /$ day for women and $>30 \mathrm{~g} /$ day for men [6]. Furthermore, in women the effects of alcohol use appear to be additive to that of the BP-rising effects of contraceptives [36].

The strong aggregate level association between vodka sale and HTN mortality rate in Russia might be an outcome of a preference for spirits among heavy drinkers [18]. Several studies have reported an increased risk of developing HTN in heavy drinkers $[21,26]$.

The findings that of the three beverages vodka alone were associated with HTN mortality in Russia supports similar results from other settings. For instance, a recent cross-sectional study from China found that, in those subjects, who predominantly consumed liquor, there was a significantly higher odds ratio for the presence of isolated systolic hypertension [37]. A similar result was reported in a study of Japanese male workers [20].

The precise mechanisms by which heavy alcohol intake increases BP and the risk of HTN remains unexplained. Binge drinking may increase BP through several potential mechanisms, such as stimulation the sympathetic nervous system and the renin-angiotensin-aldosterone system [25]. Alcohol also may increase plasma cortisol level, increase in vasoconstrictor endothelin-1 release, or decrease in NO production in the arterial endothelium [3]. Elevated level of plasma homocysteine, which has been linked to vascular damage may also contribute to the development of HTN [26].

Before concluding, several potential limitations of this study must be mentioned. In particular, we relied on official alcohol sales data as a proxy measure for trends in alcohol consumption across the period. However, the unrecorded consumption of alcohol was commonplace in Russia throughout the study period, especially in the mid-1990s, when a considerable proportion of vodka came from illicit sources $[18,28]$. Further, there was also the risk of omitted variable bias in this work.

Table 2. Estimated beverage-specific effects of alcohol sales on hypertension mortality rates.

\begin{tabular}{|c|c|c|c|c|c|c|c|c|c|}
\hline \multirow{2}{*}{ Parameter } & \multicolumn{3}{|c|}{ Vodka sales } & \multicolumn{3}{c|}{ Wine sales } & \multicolumn{3}{c|}{ Beer sales } \\
\cline { 2 - 10 }$y$ & Model & Estim. & SE & Model & Estim. & SE & Model & Estim. & SE \\
\hline $\begin{array}{c}\text { Hypertension } \\
\text { mortality males }\end{array}$ & 0.1 .0 & $0.108 * *$ & 0.010 & $0,1,0$ & 0.140 & 0.032 & $0,1,0$ & 0.210 & 0.052 \\
\hline $\begin{array}{c}\text { Hypertension } \\
\text { mortality females }\end{array}$ & 0.1 .0 & $0.091 *$ & 0.012 & $0,1,0$ & 0.002 & 0.043 & $0,1,0$ & 0.185 & 0.056 \\
\hline
\end{tabular}

$\mathrm{SE}$, standard error

$* \mathrm{p}<.05$

$* * \mathrm{p}<.01$ 
In conclusion, the present study suggests that HTN mortality tend to be more responsive to changes in spirits consumption per capita than to the wine or beer consumption. Assuming that drinking vodka is usually associated with intoxication episodes, these findings provide indirect evidence that that substantial proportion of HTN deaths in Russia are due to acute effect of binge drinking. The findings from the present study have important implications as regards alcohol policy in Russia suggesting that any attempts to reduce overall consumption should also be linked with efforts through differential taxation to shift beverage preference away from spirits.

\section{Conflict of interest}

None declared

\section{REFERENCES}

[1] Abramson J.L., Lewis C., Murray N.V. Relationship of self-reported alcohol consumption to ambulatory blood pressure in a sample of health adults. Am J Hypertension, 2010;23:994-999.

[2] Arhmedjonov A., Suvankulov F. Alcohol consumption and its impact on the risk of high blood pressure in Russia. Drug and Alcohol Review, 2013;23(3):248-253.

[3] Arkwright P.D., Beilin L.J., Vandongen R., Rouse I.A., Lalor C. The pressor effect of moderate alcohol consumption in man: a search for mechanisms. Circulation, 1982;66:515-519.

[4] Box G. E. P., \& Jenkins, G. M. Time Series Analysis: forecasting and control. London. Holden-Day Inc. 1976.

[5] Brenn T. The Tromso Heart Study: alcoholic beverages and coronary risk factors. J Epidemiol Comm Health, 1986;40(2):249-256

[6] Burger M., Bronstrup A., Pietezik K. Derivation of tolerable upper alcohol intake levels in Germany: A systematic review of risks and benefits of moderate alcohol consumption. Prev Med, 2004;39:111-127.

[7] Chen L., Smith G.D., Harbord R.M., Lewis S.J. Alcohol intake and blood pressure: a systematic review implementing a Mendelian randomized approach. PloS Medicine, 2008;5(3):e52.

[8] Corrao G., Bagnardi V., Zambon A., Arico S. Exploring the dose-response relationship between alcohol consumption and the risk of several alcohol-related conditions: a meta-analysis. Addiction, 1999;94:1551-1573.

[9] Djosse L., Mukamal K.J. Alcohol consumption and risk of hypertension: does the type of beverage or drinking pattern matter? Rev Esp Cardiol, 2009;62(6):603-605.

[10] Fuchs F.D., Chambless L.E., Whelton P.K., Nieto J., Heiss G. Alcohol consumption and the incidence of hypertension: the atherosclerosis risk in communities study. Hypertension, 2001;37:1242-1250.
[11] Global health risk. Mortality and burden of disease attributable to selected major risk. WHO Press. Genewa, 2009.

[12] Kerney P.M., Whelton M., Reynolds K., Muntner P., Whelton P.K., He J. Global burden of hypertension: analysis of worldwide data. Lancet, 2005;365(9455):217-223.

[13] Klatsky A.L. Alcohol and hypertension. Clin Chim Acta, 1996;246:91-105.

[14] Klatsky A.L., Armstrong M.A., Friedman G.D. Relation of alcoholic beverage use to subsequent coronary artery hospitalization. Am J Cardiol, 1986;58:710-714.

[15] Klatsky A.L., Friedman G.D., Armstrong M.A. The relationship between alcoholic beverage use and other traits to blood pressure: a new Kaiser Permanente study. Circulation, 1986;73:628-636.

[16] Laaticainen T. Cardiovascular risk in the Republic of Karelia, Russia: comparison of major risk factors with North Karelia. Thesis. Helsinki. National Public Health Institute. 2000.

[17] Marques-Vidal P., Arveiler D., Evans A., Amouyel P., Ferrieres J., et al. Different alcohol drinking and blood pressure relationships in France and Northern Ireland: The PRIME Study. Hypertension, 2001;38:1361-1366.

[18] Nemtsov A.V., Razvodovsky Y.E. Alcohol situation in Russia, 1980-2005. Social and Clinical Psychiatry, 2008;2:52-60.

[19] Norström T., Skog O.J. Alcohol and mortality: methodological and analytical issue in aggregate analysis. Addiction, 2001;96:5-17.

[20] Okamura T, Tanaka T, Yoshita K, et al. Specific alcoholic beverage and blood pressure in a middle-aged Japanese population: The High-risk and Population Strategy for Occupational Health Promotion (HIPOP-OHP) Strategy. J Hum Hypertens, 2004;18:9-16.

[21] Pajak A., Kozela M. Cardiovascular disease in Central and Eastern Europe. Public Health Review, 2012;33:416-435.

[22] Pajak A., Szafraniec K., Kubinova R., Malyutina S., Peasey A., Pikhart H., Nikitin Y., Marmot M., Bobak M. Binge drinking and blood pressure: cross-sectional results of the HAPIEE study. PLOS ONE , 2013;8(6):e65856.

[23] Petruchin I.S., Lunina E.Y. Cardiovascular disease risk factors and mortality in Russia: challenges and barriers. Public Health Review, 2012;33(2):436-449.

[24] Pomerleau J, McKee M, Rose R, Haerpfer CW, Rotman D, Tumanov S. Hazardous alcohol drinking in the former Soviet Union: A cross-sectional study of eight countries. Alcohol \& Alcoholism. 2008;43:351-359.

[25] Puddey I.B., Vandongen R., Beilin L.J., Rouse I.L. Alcohol stimulating of renin release in man: its relation to the hemodynamic, electrolyte and sympatho-adrenal responses to drinking. J Clin Endocrinol Metabol, 1985;61:37-42.

[26] Puddey I.B., Beilin L.J. Alcohol is bad for blood pressure. Clinical and Experimental Pharmacology and Physiology, 2006;33:847-852.

[27] Razvodovsky Y.E. Estimation of alcohol attributable fraction of mortality in Russia. Adicciones, 2012;24(3):1-7. 
[28] Razvodovsky Y.E. Unrecorded alcohol consumption: quantitative methods of estimation. Alcoholism, 2010;46(1):15-24.

[29] Razvodovsky Y.E. Beverage-specific alcohol sale and cardiovascular mortality in Russia. Journal of Environmental and Public Health, 2010:Article ID:253853

[30] Razvodovsky Y.E. Alcohol consumption and ischemic heart disease mortality in Russia. Adicciones, 2012;24:23-29.

[31] Razvodovsky Y.E. Stroke and alcohol poisoning mortality in Russia. International Journal of Cardiovascular and Cerebrovascular Disease, 2013;1(2):15-20.

[32] Seppa K., Laippala P., Sillanaukee P. Drinking pattern and blood pressure. Am J Hypertens, 1994;7:249-254.

[33] Seppa K., Sillanaukee P. Binge drinking and ambulatory blood pressure. Hypertension, 1999;33:79-82.

[34] Sesso H.D., Cook N.R., Buring J.E., Manson J.E., Gaziano
J.M. Alcohol consumption and the risk of hypertension in women and men. Hypertension, 2008;51:1080-1087.

[35] Stickley A., Leinsalu M., Andreew E., Razvodovsky Y.E., Vagero D., McKee, M. Alcohol poisoning in Russia and the countries in the European part of the former Soviet Union, 1970-2002. European Journal of Public Health, 2007;17(5):444-449.

[36] Wallace R.B., Barret-Connor E., Criqui M., Wahl P., Hoover J., Hunninqhake D., Heiss G. Alteration in blood pressure associated with combined alcohol and oral contraceptive: the Lipid Research Clinics Prevalence Study. J Chron Dis, 1982;35:251-257.

[37] Wildman R.P., Gu D.F., Muntner P, et al. Alcohol intake and hypertension subtypes in Chinese men. J Hypertension, 2005;23:737-743.

[38] Zilkers R.R., Burke V., Hodgson J.M., Barden A., Beilin L.J., Puddy I.B. Red wine and beer elevate blood pressure in normotensive men. Hypertension, 2005;45:874-879. 